\title{
Assessment of Sexual Abuse and Associated Factors Among Adolescents in High Schools, Nekemte Town, East Wollega Zone, Oromia Regional State, Western Ethiopia, 2017 Kassahun Tegegne Bidu ${ }^{1 *}$ and Zalalem Kaba Babure ${ }^{2}$
}

${ }^{1}$ Primary Health Care Unit Transform Project of East Wollega Zone, Oromia Regional State, Western Ethiopia ${ }^{2}$ Zonal Health Office, East Wollega Zone, Oromia Regional State, Western Ethiopia

\section{Abstract}

Background: Adolescent's sexual abuse is any interaction between adolescents and an adult (or another adolescent) in which the adolescents is used for the sexual stimulation of the perpetrator or an observer. Sexual abuse can include both touching and non-touching behaviors. Abusers often do not use physical force, but may use play, deception, threats, or other forms of coercion to engage adolescents and maintain their silence.

Objective: The objective of this study was to assess prevalence and associated factors of adolescents sexual abuse among adolescents in high school, Nekemte town, East Wollega Zone, Oromia Regional State, Ethiopia, 2017.

Methods: School based cross sectional study was conducted in high school of Nekemte town, using systematic random sampling technique from March $1^{\text {st }}$ to $15^{\text {th }}, 2017$. Data was collected from 377 adolescent students using structured, pre tested and self-administered questionnaire. After data collection, data was cleared, coded, checked and entered in to computer software SPSS version 20.0. Univariate, analysis was performed for frequency and percentage. Binary logistic regression analysis was done to identify factors associated with sexual abuse and these factors were taken in to multivariate analysis with $95 \%$ confidence interval.

Result: Among study participants involved in the study 126 (33.4\%) were sexually abused at least once in their life time and the remaining $251(66.6 \%)$ were not sexually abused. Factors of sexual abuse associated significantly were grade attending, Fathers occupation and Mothers' education and occupation positively associated with sexual abuse of adolescents while drinking alcohol and had sexual intercourse associated inversely.

Conclusion and recommendation: The prevalence of sexual abuse is high and needs every one's attention on its reduction. Awareness creation for families and communities on sexual abuse and education for adolescents on short and long impact of sexual abuse is recommended.

Keywords: Sexual abuse; High school; Nekemte town; East wollega zone; Adolescents; Ethiopia

Abbreviations: PMSP: Premarital Sexual Practice; RHY: Run away and Homeless Youth

\section{Introduction}

Adolescents make up roughly $20 \%$ of the total world population and in developing countries; adolescents have an even higher demographic weight. In 1995, there were 914 million adolescents living in the developing world, that is, $85 \%$ of the total number. Their number is expected to reach 1.13 billion by the year 2025 . With a lower fertility decline, Africa is expected to see its adolescent population grow much more rapidly than Asia and Latin America. Adolescence is accompanied by dramatic physical, cognitive, social, and emotional changes that present both opportunities and challenges for adolescents, families, health professionals, educators, and communities. Adolescence is a period of rapid growth: up 20\% of final adult height and 50\% of adult weight are attained, bone mass increases of $45 \%$ and dramatic bone remodeling occur [1-3].

Adolescents sexual abuse is any interaction between an adolescents and an adult (or another adolescent, youth) in which the adolescent is used for the sexual stimulation of the perpetrator or an observer. Sexual abuse can include both touching and non-touching behaviors. Touching behaviors may involve touching of the vagina, penis, breasts or buttocks, oral-genital contact, or sexual intercourse. Non-touching behaviors can include voyeurism (trying to look at an adolescent's naked body), exhibitionism, or exposing the adolescents to pornography. Abusers often do not use physical force, but may use play, deception, threats, or other forms of coercion to engage adolescents and maintain their silence. Abusers frequently employ persuasive and manipulative tactics to keep the adolescents engaged. These tactics referred to as "grooming" may include buying gifts or arranging special activities, which can further confuse the victim [4].

Lifetime prevalence rates of adolescents' sexual abuse can be categorized in to three categories of sexual abuse: non-contact abuse, contact abuse and penetrating abuse. Penetrating abuse was related to more severe abuse characteristics, less frequent disclosure, more emotional and behavioral symptoms, weaker sense of coherence and poorer self-esteem when compared to non-abuse, non-contact or contact abuse [5].

According to immediate and long-term impacts of child sexual Abuse for future indicates a wide range of psychological and interpersonal problems are more prevalent among those who have been sexually abused than among individuals with no such experiences. Childhood, adolescent and youth sexual abuse is a major risk factor for a variety of problems, both in the short term and in later adult

${ }^{*}$ Corresponding author: Kassahun Tegegne Bidu, USAID/JSI Program Officer Nekemte, Ethiopia, Tel: +251911808112; E-mail: kassahuntegegne@yahoo.com

Received March 09, 2018; Accepted May 16, 2018; Published May 20, 2018

Citation: Bidu KT, Babure ZK (2018) Assessment of Sexual Abuse and Associated Factors Among Adolescents in High Schools, Nekemte Town, East Wollega Zone, Oromia Regional State, Western Ethiopia, 2017. J Nurs Care 7: 457. doi:10.4172/2167-1168.1000457

Copyright: (C) 2016 Bidu KT, et al. This is an open-access article distributed unde the terms of the Creative Commons Attribution License, which permits unrestricted use, distribution, and reproduction in any medium, provided the original author and source are credited. 
functioning such as emotional distress (anger, depression and anxiety), interpersonal difficulties and impaired sense of self. According to this research a relationship between sexual abuse and later substance abuse among adolescent and adult survivors was identified. Sexually abused female had ten times the likelihood of a drug addiction history and two times the likelihood of alcoholism relative to a group of non-abused female clients $[6,7]$.

Another study conducted in West Gojjam zone, North West Ethiopia among in school adolescents of Shendi town on premarital sexual practice and its predictors found that $19 \%$ of adolescents had premarital sexual inter course with the mean age of first sexual intercourse 16.48 for males and 15.89 for females. Among factors associated with premarital sexual practice age greater than 20 years, living with friends or relatives, living alone and watching pornographic movies were significantly associated with premarital sexual practice (PMSP). Among study participants $71.2 \%$ of them reported as they consumed alcoholic drinks and only $1 \%$ reported "Khat" chewing at least once in their life time [8]

A study conducted in Nekemte high schools showed that $21.5 \%$ of the study participants had sexual intercourse before marriage and being male, ninth grade student and ever having sexual partner have significant positive association. While being less than 18 years of age was found to be protective factor for premarital sexual practice. In the same study, the mean age at first sexual intercourse for adolescents who engaged in the study was 16.2 years for male and 15.2 years for females [9].

\section{Statement of the problem}

Throughout the world adolescent sexual abuse can occur in different magnitude and type. Although in most countries there has been little research conducted on the problem, available data suggest that in some countries nearly one in four women may experience sexual violence by an intimate partner and up to one-third of adolescent girls report their first sexual experience as being forced. Sexual violence has a profound impact on physical and mental health. As well as causing physical injury, it is associated with an increased risk of a range of sexual and reproductive health problems, with both immediate and long-term consequences. Its impact on mental health can be as serious as its physical impact, and may be equally long lasting [10].

Sexual abuse is reported by adolescent in the general population at significantly lower rates than is reported by adolescents reproductive health studies which is a round $1 \%$ to $3 \%$ compared to $21 \%$ to $42 \%$ in general population. Sexual abuse doubles the probability of being a suicide ideation or attempter. In separate analysis, sexual abuse was found to be a significant predictor of suicide ideation and attempts in a multiple regression model of analysis that included socio-demographic factors peer suicide ideation or attempts, street victimization and externalizing (behavior problem) and internalizing behavior (anxiety and depression) [11].

In India research conducted on sexual abuse indicated that onethird of the students had experienced at least one type of sexual abuse in the previous 12 months and $6 \%$ had been forced to have sex. Of one third adolescents who reported abuse, nearly half (47\%) had experienced abuse more than once, and those who reported sexual abuse were far more likely to have also experienced other kinds of physical and verbal violence in the last 12 months prior to study [6].

According to research conducted on premarital sexual practice of adolescents and youth in Nekemte town and Shendi town indicated that $21.5 \%$ and $19 \%$ of adolescents and youth practiced premarital sex. The mean age of premarital sexual practice performed by adolescents and youth were (for male 16.2 \& 16.48 years) and (for females 15.2 and 15.89 years) at Nekemte town and Shendi town respectively $[8,9]$. Both premarital sexual practice and mean age of the study participant clearly indicate that there is a problem of sexual abuse in the population mentioned towns. Premarital sex can be performed voluntarily or involuntarily by adolescent at school, home or along a street.

Various researches have been conducted across the world to identify prevalence and associated factors of sexual abuse among adolescents and youth. The finding of these researches differs according to its geographically location, method of study design used and time at which the study conducted.

To the best of our knowledge there is limited research on sexual abuse in Nekemte town and no research done in the intended study area, Nekemte secondary school. In this study every attempt was made to clearly identify the extent of sexual abuse among adolescents and where and how they are abused.

\section{Significance of the study}

Sexual abuses in adolescents occur worldwide in general and in developing counties in particular with different severity and magnitude. Basically sexual abuse is less reported than actually in general population due to extent of its perception as well as shameful perception and ill treatment from the community.

The result of this study help health sector and education office of Nekemte town to plan on identified magnitude of sexual abuse among adolescents at school level and take preventive action to tackle social, physical and psychological problem associated with sexual abuse.

The finding of the study will also serve as a source of information for concerned bodies like planners, governmental and nongovernmental organizations who need to know and intervene about sexual abuse on adolescent at different level in the study area. Other researchers who will be interested to conduct further study on similar study subjects may also use as a base line data and information.

\section{Methods and Materials}

\section{Study area and period}

Nekemte is the capital city of East Wollega zone located $331 \mathrm{~km}$ away from Addis Ababa. The location of the town on the map is 9 degree 05 North latitude, and 36-degree 33' East longitude. The topography of the town is full of ups and downs; its altitude ranges from $1380 \mathrm{~m}$ to $2300 \mathrm{~m}$ above sea level \& the total surface area of the sub-city is estimated to be $32 \mathrm{Sq} . \mathrm{km}$. The town is geographically surrounded by four rural kebeles as: Gari Kebele in the East, Feyinerakebele in the West, Kitessa Kebele in the North and Alemikebele in the South. The climatic condition of the town is midland with annual temperature of 12-34 degree Celsius. The rain fall covers about seven months of the year with mean annual rainfall of $1850 \mathrm{~mm}$.

The total population of the town as projected from $2007 / 2008$ census is about 88,969; from which 44,340 (49.8\%) are males, and 44,627 (50.2\%) are females. Different ethnic group; Oromo, Amhara, Gurage,Tigire... etc live in the town. Different religion followers like Protestant, Orthodox, Muslim, and waaqeffat a live in the sub-city. The town is divided in to six sub-cities (kifleketema) as Darge, BekeJema, Cheleleki, Kasso, Burka Jato and Bakanisa Kasse. There are different government, private and nongovernmental organization and institutions in the town. Nekemte town has one governmental hospital three health center (2 governmental and \& 1 nongovernmental), 7 higher private clinics. The town has also different types of organizations; 15 kindergarten, 10 
primary school, 6 preparatory school (3 governmental, 3 private), 8 high school (5 governmental, 3 private), 2 technical school, 5 collages, 4 nongovernmental distance education centers, 1 government university and 3 private university collage. Common religious institutions in the town are protestant church, Orthodox Church, Mosque and Catholic Church in the decreasing order of their number. The study was conducted from March $1^{\text {st }}$ to $15^{\text {th }} 2017$.

\section{Study design}

Institutional based cross-sectional study was conducted.

\section{Source population}

All high school students in Nekemte town were the source population of the study.

\section{Study population}

Those adolescent students in selected schools and fulfill the inclusion criteria was considered as study population.

\section{Eligibility criteria}

Inclusion criteria: Adolescent students in selected high schools and those attend regular during working time.

- Those available during data collection.

\section{Exclusion criteria:}

- Adolescent students in selected high schools and those attend their class during weekend and night time.

- Those critically ill and unable to give information.

\section{Sample size determination}

The sample size was calculated by using a single population proportion formula with assumptions of $47.5 \%$ of adolescent sexual abuse (9), 95\% confidence interval, 5\% margin of error and consider $10 \%$ of non-response rate.

$$
\begin{aligned}
& n=\frac{\mathrm{Z}^{2} \mathrm{P}(1-P)}{\mathrm{d}^{2}} \\
& n=\frac{\left(1.96^{2} * 0.475\right)(1-0.475)}{0.05^{2}} \equiv 383
\end{aligned}
$$

Since the source population is less than 10,000 , correction formula is used to determine the sample size.

$$
\begin{aligned}
& n f=\frac{\mathrm{n}}{1+\mathrm{n} / \mathrm{N}} \\
& n f=\frac{383}{1+383 / 3319} \\
& =\frac{383}{1.115}=343
\end{aligned}
$$

By adding $10 \%$ non-response rate $(343+34)$ the final sample size was $=\underline{\underline{377}}$

Where, A Z-value of 1.96 used at $95 \%$ CI and d of 5\%, n=sample size, $\mathrm{P}=$ Proportion, $\mathrm{d}=$ margin of error).

\section{Sampling techniques}

Systematic random sampling technique was used to select adolescent students in Nekemte town high school. Grade $9^{\text {th }}$ to $12^{\text {th }}$ students were incorporated based on existing student roster available in the school (Figure 1).

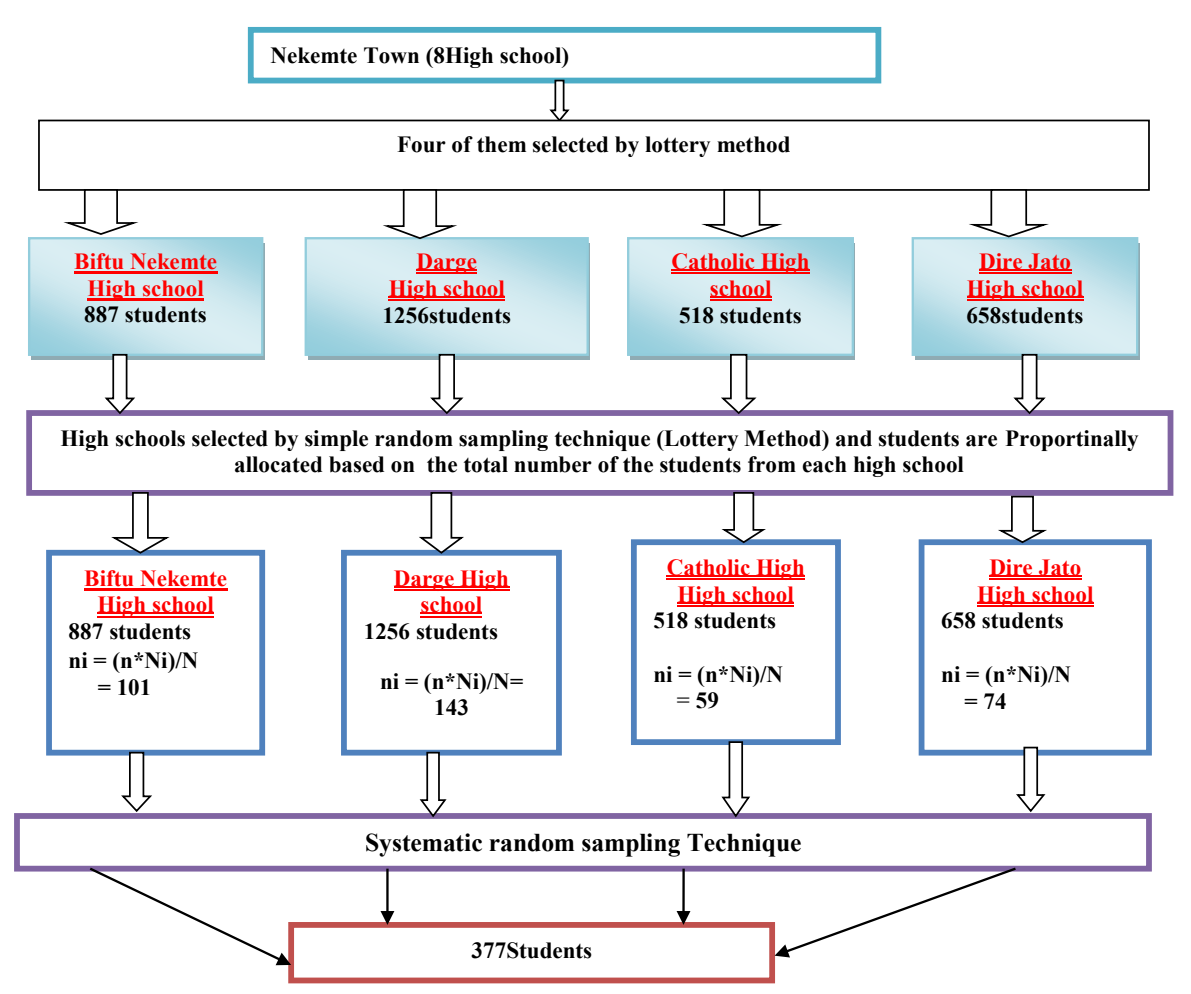

Figure 1: Schematic presentation of sampling procedures

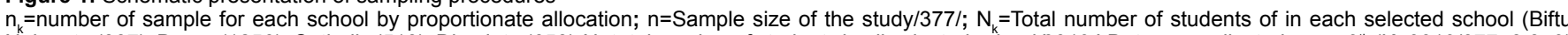
Nekemte (887), Darge (1256), Catholic (518), Dire Jato (658); $N=$ total number of students in all selected school/3319/. Data was collected every $9^{\text {th }}(K=3319 / 377=8.8=9$ ) by taking $1^{\text {st }}$ sample by lottery method. 


\section{Data collection instrument}

Data collection instrument was adopted after reviewing different literature and developed according to the study variables. It is prepared in English language and translated to Afaan Oromo by language expert and re translated to English language to check its consistency. The questionnaire has three parts; socio economic and demographic characteristics of adolescents, socio economic and demographic characteristics of parents of adolescents and factors of sexual abuse among adolescents.

\section{Pre-test}

A pretest was under taken a week before the actual data collection on 5\% sample size at Kesso high school. Based on the result the appropriate amendment was taken.

\section{Data collection procedure}

In the data collection 4 diploma nurses ( 1 for each selected school) were recruited to guide the adolescents before and during data collection. During data collection supervisor was assigned to assure the quality of data collection at spot. Adolescent students filled the questionnaire based on the guidance given for them and instruction written on the questionnaire. If the student selected is not between aged 10-19 years during time of data collection the next student was selected.

\section{Study variables}

Dependent variables:

- Sexual abuse

\section{Independent variables:}

- Socio-economic and demographic variables: Residence, marital status, ethnicity, religion, family size, monthly income, education, occupation

- Adolescent's characteristics: Age, Sex, marital status, Grade attending, own income

- Life style: life style, unhealthy life style, watching pornographic movies

\section{Operational definitions}

Abuse: Any unwanted or involuntary abuse of adolescents anywhere by whomever.

Sexual abuse: Any unwanted or involuntary abuse of adolescents anywhere by whomever for the intention of sexual action.

Associated factors: Factors significantly associated with sexual abuse of adolescents

Adolescents: Individual who are male or female aged 10-19 years.

Family size: refers to total number of people living in a house during the study period.

Income: It is periodical monthly earning from one's business, lands, work, investment etc.

\section{Data quality management}

Structured questionnaire is prepared in English language and translated to Afaan Oromo for field work purpose. Pre-test of the questionnaire was done on $5 \%$ of sample size in similar area, which is not include in study before the actual data collection to see for the accuracy of responses and to estimate time needed. On daily basis collected information was reviewed and possible errors were returned to the collectors for correction. Training and orientation was given to the data collectors and close supervision was done during data collection

\section{Data processing and analysis}

The data was checked for completeness, coded and entered in to SPSS a computer software version 20 . After edited, cleaned, and processed, it was analyzed using SPSS for window version20. Descriptive statistics of mean and standard deviation was used to examine the prevalence and associated factors of sexual abuse.

A binary logistic regression analysis was performed to determine sexual abuse and associated factors. Statistical association was checked by $95 \%$ confidence interval and crude odd ratio. The significant variables (p-value <0.05) observed in bivariate analysis was subsequently included in multivariate analysis. Finally, 95\% confidence interval and adjusted odd ratio was checked and the significance variables were taken as associated factors of sexual abuse. P-value $<0.05$ was considered as statistically significant.

\section{Ethics approval and consent to participate}

Ethical clearance was obtained from Ethical Review Board of Wollega University, College of Medical and Health sciences, Department of Nursing and midwifery. Privacy and confidentiality of collected information was ensured at all level. Respondents were asked for their willingness to participate on the study and verbal consent was obtained. The purpose of the study was clearly explained for the respondents and the study was depending on their willingness. For participating in this study the respondents was not paid an incentive and also was not be harmed.

\section{Results}

In the study 377 student adolescents were participated which makes the response rate of the study $100 \%$.

\section{Socio-economic and demographic characteristics of adolescents}

In the study sex distribution of the study participants; 167 (44.3\%) were male and $210(55.7 \%)$ were female. The mean age of the student adolescents were $17.32(\mathrm{SD} \pm 1.29)$ years with a minimum and maximum of 15 and 19 years respectively. Since only high school adolescents were included in the study their age is 15-19 years. Concerning level of education (grade adolescents attending) of the study participants; 119 (31.6\%) were $9^{\text {th }}$ grade, $143(37.9 \%)$ were $10^{\text {th }}$ grade, $82(21.8 \%)$ were $11^{\text {th }}$ grade and $33(8.8 \%)$ were $12^{\text {th }}$ grade.

Nearly half, $184(48.8 \%)$ of adolescents were protestant followed by Orthodox 129 (34.2\%) in religion and majority, 313 (83.0\%) of adolescents were Oromo by ethnicity. Regarding the marital status of student adolescents 361 (95.8\%) of them were single and only 16 (4.2\%) of adolescents were currently married. Living style of adolescents were also assessed, 241 (63.9\%), 45 (11.9\%), 69 (18.3\%) and $22(5.8 \%)$ of adolescents live with biological parents, single biological parents, friend/relative and alone respectively. Among the study participants more than three fourth $309(82.0 \%)$ do not have their own income while other $68(18.0 \%)$ of them have their own income (Table 1).

\section{Socio-economic and demographic characteristics of parents of adolescents}

Average monthly income of parents of adolescents was assessed and the mean monthly income was $2381.51(S D \pm 1513)$ ETB ranging 
Citation: Bidu KT, Babure ZK (2018) Assessment of Sexual Abuse and Associated Factors Among Adolescents in High Schools, Nekemte Town, East Wollega Zone, Oromia Regional State, Western Ethiopia, 2017. J Nurs Care 7: 457. doi:10.4172/2167-1168.1000457

Page 5 of 9

from $300.00 \mathrm{ETB}$ to $800.00 \mathrm{ETB}$ which may show variation of economic status of parents of adolescent's in the study area. The mean family size of the $\mathrm{HH}$ of adolescents was $5.56(\mathrm{SD} \pm 1.50) \mathrm{HH}$ members with minimum and maximum of 2 and $9 \mathrm{HH}$ members respectively. From $\mathrm{HH}$ of adolescents number of adolescents residing in the $\mathrm{HH}$ was also identified and the mean number of adolescents in the $\mathrm{HH}$ was 2.35 (SD \pm 0.89 ) adolescents with a range of 3 (minimum 1 and maximum 4) adolescents. The mean distance of school from home of adolescents was $2.40(\mathrm{SD} \pm 1.54) \mathrm{Km}$ with a minimum and maximum of $1 \mathrm{Km}$ and $8 \mathrm{Km}$ respectively (Table 2 ).

Educational status and occupation of both parents were assessed and except Unable to read and write 37 (9.8\%) and 41 (10.9\%) read and write only other have similar distribution which was $102(27.1 \%)$ primary, $86(22.8 \%)$ Secondary and $111(29.4 \%)$ were diploma and above level of education of the father of adolescents. Nearly one third,

\begin{tabular}{|c|c|c|c|}
\hline Variables & Response & Frequency & Percentage (\%) \\
\hline \multirow{2}{*}{ Sex of adolescents } & Male & 167 & 44.3 \\
\hline & Female & 210 & 55.7 \\
\hline \multirow{2}{*}{ Age of adolescents } & 15-17 Years & 197 & 52.3 \\
\hline & 18-19 Years & 180 & 47.7 \\
\hline \multirow{5}{*}{ Religion } & Orthodox & 129 & 34.2 \\
\hline & Muslim & 25 & 6.6 \\
\hline & Protestant & 184 & 48.8 \\
\hline & Catholic & 10 & 2.7 \\
\hline & Waaqeffata & 29 & 7.7 \\
\hline \multirow{4}{*}{ Ethnicity } & Oromo & 313 & 83.0 \\
\hline & Amhara & 42 & 11.1 \\
\hline & Gurage & 17 & 4.5 \\
\hline & Tigre & 5 & 1.3 \\
\hline \multirow{2}{*}{$\begin{array}{l}\text { Marital Status of } \\
\text { adolescents }\end{array}$} & Single & 361 & 95.8 \\
\hline & Currently married & 16 & 4.2 \\
\hline \multirow{4}{*}{$\begin{array}{l}\text { Level of education } \\
\text { (Grade adolescents } \\
\text { attending ) }\end{array}$} & $9^{\text {th }}$ grade & 119 & 31.6 \\
\hline & $10^{\text {th }}$ grade & 143 & 37.9 \\
\hline & $11^{\text {th }}$ grade & 82 & 21.8 \\
\hline & $12^{\text {th }}$ grade & 33 & 8.8 \\
\hline \multirow{4}{*}{$\begin{array}{l}\text { With whom do } \\
\text { adolescents live? }\end{array}$} & $\begin{array}{l}\text { Both biological } \\
\text { parent }\end{array}$ & 241 & 63.9 \\
\hline & $\begin{array}{l}\text { Single biological } \\
\text { parent }\end{array}$ & 45 & 11.9 \\
\hline & Friends or relatives & 69 & 18.3 \\
\hline & Alone & 22 & 5.8 \\
\hline \multirow{2}{*}{$\begin{array}{l}\text { Do you have your own } \\
\text { income? }\end{array}$} & Yes & 68 & 18.0 \\
\hline & No & 309 & 82.0 \\
\hline
\end{tabular}

Table 1: Socio-economic and demographic characteristics of adolescents Nekemte High school, East Wollega, Oromia, Ethiopia, March 2017.
$125(33.2 \%)$ of father of adolescents were daily laborer, more than one fourth, 109 (28.9\%) has private business, $102(27.1 \%)$ were government employee by occupation. Regarding educational status of mother of adolescents $114(30.2 \%)$ and $86(22.8 \%)$ had primary and secondary education. The occupation of mother of adolescents, nearly one third, $121(32.1 \%)$ were housewife, $89(23.6 \%)$ were daily laborer and 79 (21.0\%) had private business (Figure 2).

\section{Sexual abuse and sexual characteristics of adolescent}

Among study participants involved in the study 126 (33.4\%) were sexually abused at least once in their life time. Type of sexual abuse adolescents faced was mental (psychological) abuse followed by

\begin{tabular}{|c|c|c|c|}
\hline Variables & Responses & Frequency & Percentage (\%) \\
\hline \multirow{6}{*}{$\begin{array}{l}\text { Occupation of mother } \\
\text { of adolescents }\end{array}$} & Daily laborer & 89 & 23.6 \\
\hline & Government employee & 56 & 14.9 \\
\hline & House wife & 121 & 32.1 \\
\hline & Employed in private sector & 16 & 4.2 \\
\hline & Has private business & 79 & 21.0 \\
\hline & Unemployed & 16 & 4.2 \\
\hline \multirow{5}{*}{$\begin{array}{l}\text { Occupation of father } \\
\text { of adolescents }\end{array}$} & Daily laborer & 125 & 33.2 \\
\hline & Government employee & 102 & 27.1 \\
\hline & Employed in private sector & 31 & 8.2 \\
\hline & Has private business & 109 & 28.9 \\
\hline & Unemployed & 10 & 2.7 \\
\hline \multirow{3}{*}{$\begin{array}{l}\text { Marital status of } \\
\text { parents of adolescents }\end{array}$} & Currently married & 350 & 92.8 \\
\hline & Divorced & 12 & 3.2 \\
\hline & Widowed & 15 & 4.0 \\
\hline \multirow{2}{*}{$\begin{array}{l}\text { Current residence of } \\
\text { parents of adolescents }\end{array}$} & Urban & 271 & 71.9 \\
\hline & Rural & 106 & 28.1 \\
\hline \multirow{4}{*}{$\begin{array}{l}\text { Total adolescents in } \\
\text { the household }\end{array}$} & One & 68 & 18.0 \\
\hline & Two & 144 & 38.2 \\
\hline & Three and above & 127 & 33.7 \\
\hline & No adolescent except & 38 & 10.1 \\
\hline \multirow{3}{*}{$\begin{array}{l}\text { Family size of } \mathrm{HH} \text { of } \\
\text { adolescents }\end{array}$} & Small family (1-3) & 26 & 6.9 \\
\hline & Medium family (4-6) & 254 & 67.4 \\
\hline & Large family (7-9) & 97 & 25.7 \\
\hline \multirow{5}{*}{$\begin{array}{l}\text { Average monthly } \\
\text { income of } \mathrm{HH} \text { of } \\
\text { adolescents }\end{array}$} & $<$ or=500 ETB & 27 & 7.2 \\
\hline & 501 to 1500 ETB & 129 & 34.2 \\
\hline & 1501 to 3000 ETB & 136 & 36.1 \\
\hline & 3001 to 4500 ETB & 38 & 10.1 \\
\hline & 4501 and above ETB & 47 & 12.5 \\
\hline \multirow{3}{*}{$\begin{array}{l}\text { School distance from } \\
\text { home }\end{array}$} & 1 to $3 \mathrm{Km}$ & 298 & 79.0 \\
\hline & 4 to $6 \mathrm{Km}$ & 73 & 19.4 \\
\hline & 7 and above $\mathrm{Km}$ & 6 & 1.6 \\
\hline
\end{tabular}

Table 2: Socio-economic and demographic characteristics of parents of adolescents, Nekemte high school, East Wollega, Oromia, Ethiopia, March 2017.

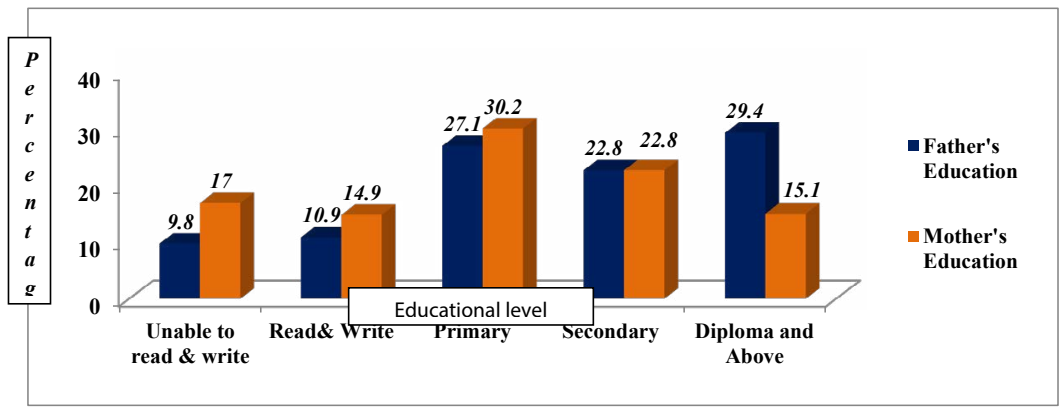

Figure 2: Educational status of parents of adolescents, Nekemte High School, East Wollega, Oromia, Ethiopia, March 2017. 


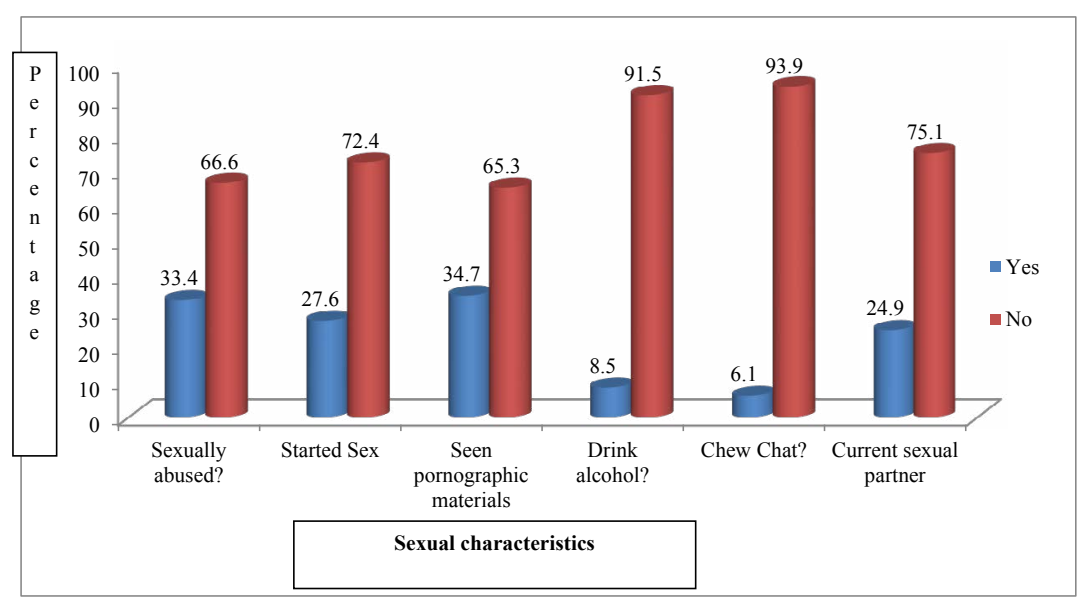

Figure 3: Sexual characteristics of adolescents, Nekemte High school, East Wollega, Oromia, Ethiopia, March 2017.

\begin{tabular}{|c|c|c|c|}
\hline Variables & Response & Number & Percentage (\%) \\
\hline \multirow{2}{*}{$\begin{array}{l}\text { Have you ever } \\
\text { sexually abused? }\end{array}$} & Yes & 126 & 33.4 \\
\hline & No & 251 & 66.6 \\
\hline \multirow{5}{*}{$\begin{array}{l}\text { Type of sexual abuse } \\
\text { face by adolescents }\end{array}$} & Attempted rape & 24 & 19.0 \\
\hline & Forced (coerced) sex & 10 & 7.9 \\
\hline & Physical abuse & 32 & 25.4 \\
\hline & Mental (psychological) abuse & 55 & 43.7 \\
\hline & Other & 5 & 4.0 \\
\hline \multirow{2}{*}{$\begin{array}{l}\text { Time at which } \\
\text { adolescents sexual } \\
\text { abuse }\end{array}$} & Day time & 89 & 70.6 \\
\hline & Night time & 37 & 29.4 \\
\hline \multirow{4}{*}{$\begin{array}{l}\text { Lace where } \\
\text { adolescents sexually } \\
\text { abused }\end{array}$} & At home & 25 & 19.8 \\
\hline & In school & 24 & 19.0 \\
\hline & Out of school & 39 & 31.0 \\
\hline & Other Place & 38 & 30.2 \\
\hline \multirow{4}{*}{$\begin{array}{l}\text { Relation of } \\
\text { adolescents to sexual } \\
\text { abuser }\end{array}$} & Acquaintance & 56 & 44.4 \\
\hline & Friends (School boy/girl) & 31 & 24.6 \\
\hline & Out of school boy/girl & 18 & 14.3 \\
\hline & Relatives & 21 & 16.7 \\
\hline \multirow{4}{*}{$\begin{array}{l}\text { Age of sexual } \\
\text { abuser in relation to } \\
\text { adolescents }\end{array}$} & Younger than the respondents & 1 & 0.8 \\
\hline & The same age a respondents & 38 & 30.2 \\
\hline & Older than the respondents & 55 & 43.7 \\
\hline & Unknown & 32 & 25.4 \\
\hline \multirow{6}{*}{$\begin{array}{l}\text { Action taken by victim } \\
\text { of sexual abuse }\end{array}$} & Nothing & 19 & 15.1 \\
\hline & Verbal retaliation & 24 & 19.0 \\
\hline & Run Away & 23 & 18.3 \\
\hline & Physical retaliation & 15 & 11.9 \\
\hline & Avoided (ended friendship) & 20 & 15.9 \\
\hline & Told parent & 25 & 19.8 \\
\hline \multirow{2}{*}{$\begin{array}{l}\text { Ever started sexual } \\
\text { intercourse? }\end{array}$} & Yes & 104 & 27.6 \\
\hline & No & 273 & 72.4 \\
\hline \multirow{7}{*}{ Reason to start sex } & Fall in love & 38 & 36.5 \\
\hline & Desire to practice sex & 7 & 6.7 \\
\hline & Got married & 14 & 13.5 \\
\hline & Forced (coerced) & 4 & 3.8 \\
\hline & Material gift & 14 & 13.5 \\
\hline & Peer pressure & 19 & 18.3 \\
\hline & Dunked & 8 & 7.7 \\
\hline \multirow{3}{*}{$\begin{array}{l}\text { Age at first sexual } \\
\text { intercourse }\end{array}$} & $<15$ Years & 12 & 11.5 \\
\hline & 15-17 Years & 68 & 65.4 \\
\hline & > or=18 Years & 24 & 23.1 \\
\hline
\end{tabular}

Table 3: Sexual abuse and sexual characteristics of adolescent, Nekemte high school East Wollega, Oromia, Ethiopia, March 2017. physical abuse and attempted rape which accounts for 55 (43.7\%), 32 (25.4\%) and $24(19.0 \%)$ respectively. Place where adolescents abused according to its decreasing order were, out of school 39 (31.0\%), other place $38(30.2 \%)$, at home $25(19.8 \%)$ and in school accounting 24 (19.0\%). Among respondents, nearly three fourth, 89 (70.6\%) of were sexually abused during day time and the rest 37 (29.4\%) were abused at night.

Among adolescents participated in the study majority of them, 345 (91.5\%) do not drink. Chat chewing characters of adolescent were also assessed and majority 354 (93.9\%) of adolescents do not chew chat as well $131(34.7 \%)$ of adolescents seen pornographic materials. From a total of adolescents, 104 (27.6\%) had sexual intercourse and the remaining 273 (72.4\%) responded that they did not started sexual intercourse. Reason to start sex by adolescents, 38 (36.5\%) were fall in love and age at which they started sex, two third, $68(65.4 \%)$ was 15 to 17 years. Ninety four (24.9\%) of adolescents currently have sexual partner and the other did not. Among respondents who have sex partner currently, number of sexual partner were $75(79.8 \%)$ one, $9(9.6 \%)$ two and $10(10.6 \%)$ had three sexual partner (Figure 3) (Table 3).

\section{Factors associated with sexual abuse of adolescents}

Different variables were assessed to identify factors associated with sexual abuse of adolescent students in the study area. Binary logistic regression analysis was employed in the identification of the factors using computer software. On bivariate analysis adolescent level of education, educational status of father and mother, occupation of father and mother, residence, alcohol consumption, chewing chat, seeing pornographic materials, had sexual intercourse and having current sexual partner were significantly associated with sexual abuse of adolescents.

Factors significantly associated with sexual abuse of adolescents in bivariate analysis were taken to multivariate analysis of regression. After running multivariate analysis factors significantly associated with sexual abuse of adolescents were adolescents' level of education (grade they are attending), Fathers' occupation, mothers' educational status and occupation, alcohol consumption and had started sexual intercourse.

Regarding grade adolescents attending, being in grade $10^{\text {th }} 2.85$ $(95 \%$ CI $1.01,8.14)$, grade $11^{\text {th }} 6.93(95 \%$ CI $2.41,19.9)$ and grade $12^{\text {th }}$ 3.218 (95\% CI 1.07, 9.62) are high risk for sexual abuse when compared 
Citation: Bidu KT, Babure ZK (2018) Assessment of Sexual Abuse and Associated Factors Among Adolescents in High Schools, Nekemte Town, East Wollega Zone, Oromia Regional State, Western Ethiopia, 2017. J Nurs Care 7: 457. doi:10.4172/2167-1168.1000457

Page 7 of 9

\begin{tabular}{|c|c|c|c|c|c|}
\hline \multirow{2}{*}{ Variables } & \multirow{2}{*}{ Response } & \multicolumn{2}{|c|}{ Sexually Abused } & \multirow{2}{*}{ COR(95\%Cl) } & \multirow{2}{*}{ AOR $(95 \% \mathrm{Cl})$} \\
\hline & & Yes & No & & \\
\hline \multirow{4}{*}{$\begin{array}{l}\text { Adolescent's Level of } \\
\text { education }\end{array}$} & $9^{\text {th }}$ grade & $39(10.3 \%)$ & $80(21.2 \%)$ & 1 & 1 \\
\hline & $10^{\text {th }}$ grade & $38(10.1 \%)$ & $105(27.9 \%)$ & $1.34(0.79,2.29)$ & $2.85(1.01,8.14)$ \\
\hline & $11^{\text {th }}$ grade & $31(8.2 \%)$ & $51(13.5 \%)$ & $0.80(0.44,1.44)$ & $6.93(2.41,19.9)$ \\
\hline & $12^{\text {th }}$ grade & $18(4.8 \%)$ & $15(4.0 \%)$ & $0.41(0.18,0.89)$ & $3.218(1.07,9.62)$ \\
\hline \multirow{5}{*}{$\begin{array}{l}\text { Educational status of } \\
\text { father }\end{array}$} & Unable to read and write & $18(4.8 \%)$ & $19(5.0 \%)$ & $0.35(0.16,0.77)$ & $1.43(0.33,6.22)$ \\
\hline & Read \& write only & $15(4.0 \%)$ & $26(6.9 \%)$ & $0.58(0.27,1.25)$ & $2.77(0.76,9.99)$ \\
\hline & Primary $\left(1-8^{\text {th }}\right)$ & $34(9.0 \%)$ & $68(18.0 \%)$ & $0.67(0.37,1.22)$ & $1.73(0.62,4.84)$ \\
\hline & Secondary $\left(9-12^{\text {th }}\right)$ & $31(8.2 \%)$ & $55(14.6 \%)$ & $0.59(0.32,1.10)$ & $1.53(0.60,3.93)$ \\
\hline & Diploma and above & $28(7.4 \%)$ & $83(22.0 \%)$ & 1 & 1 \\
\hline \multirow{5}{*}{ Father's occupation } & Daily laborer & $56(14.9 \%)$ & $69(18.3 \%)$ & 1 & 1 \\
\hline & Gov't employee & $22(5.8 \%)$ & $80(21.2 \%)$ & $2.95(1.63,5.31)$ & $3.02(1.01,9.05)$ \\
\hline & Private sector employee & $7(1.9 \%)$ & $24(6.4 \%)$ & $2.78(1.11,6.93)$ & $2.62(0.72,9.56)$ \\
\hline & Private business & $38(10.1 \%)$ & $71(18.8 \%)$ & $1.51(0.89,2.57)$ & $0.83(0.35,1.97)$ \\
\hline & Unemployed & $3(0.8 \%)$ & $7(1.9 \%)$ & $1.89(0.46,7.66)$ & $1.09(0.19,6.27)$ \\
\hline \multirow{5}{*}{$\begin{array}{l}\text { Educational status of } \\
\text { mother }\end{array}$} & Unable to read and write & $27(7.2 \%)$ & $37(9.8 \%)$ & $0.32(0.14,0.74)$ & $0.36(0.07,1.75)$ \\
\hline & Read \& write only & $25(6.6 \%)$ & $31(8.2 \%)$ & $0.29(0.12,0.68)$ & $0.17(0.04,0.72)$ \\
\hline & Primary $\left(1-8^{\text {th }}\right)$ & $41(10.9 \%)$ & $73(19.4 \%)$ & $0.42(0.19,0.91)$ & $0.15(0.04,0.56)$ \\
\hline & Secondary $\left(9-12^{\text {th }}\right)$ & $22(5.8 \%)$ & $64(17.0 \%)$ & $0.69(0.30,1.57)$ & $0.38(0.11,1.34)$ \\
\hline & Diploma and above & $11(2.9 \%)$ & $46(12.2 \%)$ & 1 & 1 \\
\hline \multirow{6}{*}{ Mother's occupation } & Daily laborer & $42(11.1 \%)$ & $47(12.5 \%)$ & 1 & 1 \\
\hline & Gov't employee & $14(3.7 \%)$ & $42(11.1 \%)$ & $2.68(1.28,5.58)$ & $0.70(0.19,2.54)$ \\
\hline & House wife & $34(9.0 \%)$ & $87(23.1 \%)$ & $2.28(1.28,4.06)$ & $1.77(0.76,4.15)$ \\
\hline & Private sector employee & $8(2.1 \%)$ & $8(2.1 \%)$ & $0.89(0.30,2.59)$ & $0.21(0.04,0.98)$ \\
\hline & Private business & $26(6.9 \%)$ & $53(14.1 \%)$ & $1.82(0.97,3.41)$ & $1.14(0.40,3.25)$ \\
\hline & Unemployed & $2(0.5 \%)$ & $14(3.7 \%)$ & $6.25(1.34,29.14)$ & $1.98(0.33,11.74)$ \\
\hline \multirow{2}{*}{ Residence } & Urban & $79(21.0 \%)$ & $192(50.9 \%)$ & 1 & 1 \\
\hline & Rural & $47(12.5 \%)$ & $59(15.6 \%)$ & $0.51(0.32,0.82)$ & $0.66(0.34,1.29)$ \\
\hline \multirow{2}{*}{ Drink alcohol? } & Yes & $23(6.1 \%)$ & $9(2.4 \%)$ & 1 & 1 \\
\hline & No & $103(27.3 \%)$ & $242(64.2 \%)$ & $6.00(2.68,13.42)$ & $4.07(1.37,12.08)$ \\
\hline \multirow{2}{*}{ Chew Chat? } & Yes & $14(3.7 \%)$ & $9(2.4 \%)$ & 1 & 1 \\
\hline & No & $112(29.7 \%)$ & $242(64.2 \%)$ & $3.36(1.41,7.99)$ & $1.06(0.30,3.70)$ \\
\hline \multirow{2}{*}{$\begin{array}{l}\text { Seen pornographic } \\
\text { movies }\end{array}$} & Yes & $66(17.5 \%)$ & $65(17.2 \%)$ & 1 & 1 \\
\hline & No & $60(15.9 \%)$ & $186(49.3 \%)$ & $3.14(2.00,4.93)$ & $1.61(0.89,2.89)$ \\
\hline \multirow{2}{*}{$\begin{array}{l}\text { Had sexual } \\
\text { intercourse? }\end{array}$} & Yes & $69918.3 \%)$ & $35(9.3 \%)$ & 1 & 1 \\
\hline & No & $57(15.1 \%)$ & $216(57.3 \%)$ & $7.47(4.52,12.32)$ & $7.00(2.73,17.94)$ \\
\hline \multirow{2}{*}{$\begin{array}{l}\text { Have current sex } \\
\text { partner? }\end{array}$} & Yes & $69(18.3 \%)$ & $35(9.3 \%)$ & 1 & 1 \\
\hline & No & $57(15.1 \%)$ & $216(57.3 \%)$ & $5.09(3.09,8.37)$ & $1.30(0.49,3.47)$ \\
\hline
\end{tabular}

Table 4: Factors associated with sexual abuse among adolescent students, Nekemte High school, February, 2017.

to attending grade $9^{\text {th }}$. This could be due to increase in age of adolescents and as well as sexual need of the adolescents. Fathers occupation was among factors associated with sexual abuse of adolescents and adolescents whose their father is government employee is three times $(3.02(95 \%$ CI $1.01,9.05))$ at risk than adolescents whose their father is daily laborer.

Mothers' education was significantly associated with adolescents sexual abuse and adolescents whose mother read \& write only $(0.17(95 \%$ CI $0.04,0.72))$ and attended primary $\left(1-8^{\text {th }}\right.$ grade $)$ school $(0.15(95 \%$ CI $0.04,0.56)$ ) was at less risk when compared to adolescents whose mother attended diploma and above level of education. In multivariate analysis mothers' occupation was associated and an adolescent whose mother was employed in private sector was at less risk when compared to whose mother are daily laborers.

In the study drinking alcohol was inversely associated with sexual abuse and those adolescents who do not drink alcohol are four times $(4.07(95 \%$ CI $2.68,13.42))$ at risk to be sexually abused than those who drink alcohol. Adolescents who did not had sexual intercourse are seven folds $(7.00$ (95\% CI 2.73, 17.94)) at risk than adolescents who had sexual intercourse. This can due to respect married adolescents get from their peer after engaging in marriage or being dated for marriage (Table 4).

\section{Discussion}

Among study participants involved in the study 126 (33.40\%) of adolescent students were sexually abused with different type of sexual abuse at various places. Globally about $14 \%$ of adolescents are sexually abused in school sometimes in their lives and only $10 \%$ adolescents report as sexually abused among out of school and more boys than girls are sexually abused during early adolescent age than late adolescent. In this study females than males (46.8\% versus $53.2 \%)$ are slightly sexually abused. When compared with the global prevalence it is much higher. The discrepancy could be due to large sample size and economic difference in various countries [12].

But prevalence of sexual abuse among adolescents in current study 
is less than that of study conducted on homeless adolescents which ranges from $75 \%$ to $89 \%$. Among study participants sexually abused $56(44.4 \%)$ of them were abused by someone they do not knew which is higher than that of homeless adolescents. This may show that sexual abuse among homeless adolescent very high when compared to those adolescents living with their parents. In addition, the variation in prevalence of sexual abuse among adolescents could be due to variation in study design and study area since study design of sexual abuse among homeless was longitudinal [13].

The finding of this study showed that 126 (33.4\%) of adolescents were sexually abused which almost similar to study conducted among young people of South Africa which was $35.4 \%$. The main impacts of sexual abuse on adolescents were social and emotional development and health and wellbeing of adolescents. The rate of sexual abuse and reported prevalence of sexual abuse was disproportionate and less was reported in different countries including the current study $[14,15]$.

As in other developing countries many of adolescents have been victimized by sexual abuse and used different defensive mechanism against sexual abuse. Some of adolescents did nothing while others run away and retaliation (verbal/physical). In similar study conducted in Bangladesh indicated that adolescents are often too ashamed or frightened to complain as they are being sexually abused. This could be due to perception of our community in which we are living or could be taken as a normal phenomenon by the community due to lack of awareness on its impact [16]. Peer (in school or out of school) sexual assault also reported in this study with $24.6 \%$ and $14.7 \%$ respectively that had similarity with study conducted in Southeastern Michigan with $26 \%$ of high school boy sexual assault by peers [17]

In this study $352(80.2 \%)$ of adolescents did not disclosed sexual abuse to any one and took their own action whereas only $25(19.8 \%)$ of adolescent students disclosed sexual abuse to their parents. Also in this study none of adolescent students notified their sexual abuse police while in United State about $5.7 \%$ of sexual abuse notified police. In general population sexual abuse is reported in lower rate than actual happen by adolescents [11,17]. In general population the prevalence of sexual abuse is estimated to be $21 \%$ to $42 \%$ while reported sexual abuse is about $1 \%$ to $3 \%$ [11]. The disclosure of sexual abuse among developed country was unacceptably high when compared to developing country. In United State about $42 \%$ of males never have disclosed the experience of sexual abuse and $33 \%$ of female adolescents never disclosed their sexual abuse to anyone. This number is very high and needs consideration on disclosure and notification of sexual abuse to concerned bodies for prevention of further sexual abuse among adolescent students $[11,17,18]$.

In this study adolescent students experienced sexual abuse at the hands of a family member $21(16.7 \%)$, or by someone outside of the family $356(83.3 \%)$ which have great psychological impact later in their social, educational and economic life. Most of the time researches are conducted on sexual abuse and health outcome of young people including children and adolescents in developed country than that of developing country $[16,17,19]$.Adolescent and youth sexual abuse is a major risk factor for a variety of problems, both in the short term and in later adult functioning such as emotional distress (anger, depression and anxiety), interpersonal difficulties and impaired sense of self [7]. Young people including adolescents who are sexually abused are at risk for short term and lifelong negative sexual outcomes. Among the negative sexual health outcome; teen pregnancy, STI including HIV infection, substance use and abuse, domestic violence or physical abuse, and risk taking behavior are the commonest [19].
Developing countries face great challenges from impact of sexual abuse that occur during adolescence. In this study among all study participants $59(15.6 \%)$ of male and $67(16.7 \%)$ of female were sexual abused that is higher than study conducted in India with $7.84 \%$ and $13.53 \%$ for male and female respectively. Adolescents who had reported sexual intercourse in current study was $66(17.5 \%)$ male and $38(10.1 \%)$ female from total of study participants while in India it was about $6.31 \%$ and $1.31 \%$ for male and female respectively. Ranges for the age at first sexual inter course varies from study and to study while in current study $68(65.4 \%)$ of adolescents started sexual intercourse at the age of 15-17 years while average at first sexual intercourse was 15.25 years for boys and 16.66 years for girls in study conducted in India [20]. The difference in prevalence of sexual abuse in the study could be difference in study design or nature of the population of study area or else could be variation in socio-economic development status of the population. Age at first sex is almost similar for both study population.

In this cross sectional study prevalence of sexual abuse is $33.4 \%$. Penetrating abuse was related to more severe abuse characteristics, less frequent disclosure, more emotional and behavioral symptoms, weaker sense of coherence and poorer self-esteem when compared to non-abuse, non-contact or contact abuse [5]. Magnitude of lifetime sexual abuse among adolescents and youth varies from study to study as well as from country to country. The risk of sexual abuse in lifetime increases as age of adolescent increases in the study conducted through telephone in USA was $26.6 \%$ which increases from $16.8 \%$ for 15 years to $26.6 \%$ for 17 years adolescents [21].

In current study prevalence of alcohol drinking and chat chewing among adolescents was $8.5 \%$ and $6.1 \%$ respectively while in West Gojjam zone of Shendi town was $71.2 \%$ and $1 \%$ respectively [8]. According to this study factor of sexual abuse among adolescents was level of education, mothers and fathers' occupation, mothers' educational status, alcohol consumption and having sexual intercourse significantly associated. In different study drug addiction and substance abuse [7], alcohol drinking, watching pornographic materials and life with friends, relative or alone [8] are significantly associated with sexual abuse of adolescents.

In current study the prevalence of having sexual intercourse was $104(27.6 \%)$ In similar study area, Nekemte high school, prevalence of sexual intercourse before marriage was $21.5 \%$ and as a factor being male, ninth grade student and ever having sexual partner have significant positive association with sexual abuse. Age at first sex is almost in the same range for both male and female participants. This could be due to similarity in the study subject and study area, Nekemte town high school [9]. Sexual abuse is positively associated with suicide ideation and attempts among adolescents. Also Impact of sexual abuse on adolescents were found that street victimization and externalizing (behavior problem) and internalizing behavior (anxiety and depression) in various study and also estimated to be found in this finding [11].

\section{Limitation of the study}

Since the main aim of the study was to investigate sexual abuse and associated factors among adolescents in Nekemte town high school, East Wollega zone, it does not include all the eligible participants other than sample due to lack of adequate time and resource for it. There may be recall bias and social desirability bias in the study participants.

\section{Conclusion and recommendation}

\section{Conclusion}

The finding of this study showed that many adolescent students were 
sexually abused by different type of abuser at various place. Even though it is high the actual prevalence of sexual abuse among adolescents could be greater than reported. Because there is low disclosure and report of sexual abuse by adolescents than that occurs in the population in which the adolescents live. Prevalence of sexual abuse among in school adolescents needs due attention since it hinder education.

Factors of sexual abuse in this study was found to be level of education of adolescents, mothers' education and occupation and fathers' occupation positively associated with sexual abuse and had sexual intercourse and alcohol drinking inversely associated with sexual abuse.

\section{Recommendation}

\section{For families, teachers and concerned others:}

- $\quad$ Since reported prevalence of sexual abuse among adolescent students was high families, teachers and other concerned bodies should work on reduction of sexual abuse.

- Since the source of income of the father and mother depends on their occupation and associated with sexual abuse of adolescents improving the occupation as well as income of the family through income generating activities by government bodies is needed.

- For reduction of sexual abuse among in school and out of school adolescents it is recommended that creating awareness on magnitude and severity of sexual abuse is very mandatory.

\section{For education and health sectors}

- Providing sexual and reproductive health education for adolescents giving due attention on short and long term impact of sexual abuse.

- When sexual abuse occurs, there should be way of notifying to families and concerned others in general and for police specifically.

\section{Acknowledgement}

The authors would like to thank Nekemte town secondary school for providing us back ground data of the school needed for our proposal writing. Next, we would like to extend our heartfelt thanks to all study participants, and data collectors for their genuine participation and information in the study. Lastly, but not the least, we would like to acknowledge our families for their psychological and financial support to accomplish this thesis.

\section{Competing Interests}

'The authors declare that they have no competing interests'. There was no financial interest between the research area community and us. Between the researchers, we have no any form of competing financial and non-financial interest.

\section{Authors' Contributions}

"ZK participated in conception and design, proposal development, gathering data, performing the statistical analyses and interpretation of data in addition to drafting the manuscript for important intellectual content. KT coordinated and developed the study, proposal development, guided overall stage of the research and execution, commented on the principal idea of the paper, reviewed the statistical analyses and drafted the manuscript for important intellectual content. An author and co-author of this paper have read and approved the final version before manuscript submission".

\section{References}

1. World Health Organization (2008) Adolescent friendly health services. An agenda for change, Geneva: WHO Publications.

2. World Health Organization (2010) Nutrition in adolescence Issues and challenges for the health sector, issues in adolescent health and development WHO discussion papers on adolescence.

3. Giuseppina D (2000) Nutrition in adolescence. Pediatrics in Review 21: 32-33.

4. NCTS organization (2011) Child sexual abuse fact sheet. The national child traumatic stress network.

5. Priebe, Gisela (2009) Adolescents' experiences of sexual abuse - Prevalence, abuse characteristics, disclosure, health and ethical aspects. Lund University 44: 1-44.

6. Patel V, Andrews G, Pierre T, Kamat N (2010) Gender, sexual abuse and risk behaviours in adolescents: A cross-sectional survey in schools in Goa, India. London School of Hygiene \& Tropical Medicine.

7. Briere JN, Elliott DM (2009) Immediate and long-term impacts of child sexual abuse. Future 4: 54-69.

8. Bogale A, Seme A (2014) Premarital sexual practices and its predictors among in-school youths of Shendi town, west Gojjam zone, North Western Ethiopia. Reprod Health 11: 49.

9. Assefa S, Dessalegn W (2008) Premarital sexual practice among schoo adolescent in Nekemte Town, East Wollega, Ethiopia. Ethiop J Health Dev 20:

10. Hakimi M (2008) Silence for the sake of harmony: domestic violence and women's health in central, Java. Gadjah Mada University, Yogyakarta.

11. Astbury $\mathrm{J}$ (2013) Child sexual abuse in the general community and clergy perpetrated. Australian Psychological Society.

12. Thalagala N (2004) National survey on emerging issues among adolescents in Sri Lanka, UNICEF Sri Lanka.

13. Greene JM, Sanchez R (2010) Sexual abuse among homeless adolescents: Prevalence, correlates and sequelae. The administration on children, youth and families, USA.

14. The John Jay College of Criminal Justice (2004) Nature and scope of sexua abuse of minors by catholic priests and deacons in the United States 19502002. The City University of New York.

15. Rowland M (2011) Sexual health disparities among disenfranchised youth, USA.

16. Janaina Barbosa de Oliveira (2013) Sexual abuse and alcohol use among women in metropolitan Sao Paulo, Brazil: A general population studies. Rev Bras Epidemiol 16: 817-825.

17. Jahan KN (2011) Sexual abuse problems among adolescents and major remedial actions, In the case of Bangladesh. IJBB 1: 1-19.

18. Young AM, Grey M, Boyd CJ (2009) Adolescents' experiences of sexual assault by peers: Prevalence and nature of victimization occurring within and outside of school. J Youth Adolescence 38: 1072-1083.

19. Ramadugu S, Ryali V, Srivastava K, Bhat BS, Prakash J (2011)Understanding sexuality among Indian urban school adolescents. Ind Pschiatry J 20: 49-55.

20. Lillian Artz (2016) Sexual abuse of children and adolescents in South Africa, UBS AG, Publications Management \& Creative Solutions, Zurich.

21. Finkelhor D, Shattuck A, Turner HA, Hamby SL (2014) The lifetime prevalence of child sexual abuse and sexual assault assessed in late adolescence. J Adolesc Health 55: 329-33. 